\title{
Mixing damp and wet basalts in the deep arc crust: a new recipe to form uniform differentiated arc melts?
}

\author{
HERVÉ REZEAU ${ }^{1}$, BENJAMIN Z. KLEIN ${ }^{2}$ AND OLIVER \\ JAGOUTZ ${ }^{1}$ \\ ${ }^{1} \mathrm{MIT}$ \\ ${ }^{2}$ Boston College \\ Presenting Author: hrezeau@mit.edu
}

Arc crust is traditionally defined by an intermediate to felsic upper crust and a complementary lower crust dominated by dense ultramafic-mafic cumulates. The nature of lower crustal cumulates either reflect crystallization-differentiation of basaltic arc magma or partial melting of preexisting crust or a combination of both. These formation processes remain unclear and ultimately influence the composition of the derivative melts that form the bulk of the continental crust.

The southern Sierra Nevada exposes the Bear Valley Intrusive Suite (BVIS) that represents a $30 \mathrm{~km}$-thick continuous crustal section. Our previous work showed that the bulk of this crustal section was emplaced within $1.39 \pm 0.06$ Myr. The deepest portion of the BVIS includes mafic cumulates consisting of hornblende norite, hornblende gabbronorite, hornblende gabbro and hornblendite that formed at $\sim 8-9$ kbars and crystallized during isobaric cooling between $\sim 1050^{\circ} \mathrm{C}$ and $\sim 810^{\circ} \mathrm{C}$. Shallower crustal levels are dominated by tonalites emplaced from $\sim 6-7$ to $\sim 2-3$ kbars at temperatures ranging from $\sim 780^{\circ} \mathrm{C}$ to $\sim 720^{\circ} \mathrm{C}$.

Petrography and mineral chemistry reveal different sequences of mineral crystallization for each type of gabbro that suggest coeval parental melts of contrasting compositions and $\mathrm{H}_{2} \mathrm{O}$ contents that vary from $\sim 1.5$ to $>3 \mathrm{wt} \%$. Despite this diversity in the lower crust, the tonalite middle and upper crust represent comparatively homogeneous liquids that are temporally and genetically related to the igneous mafic cumulates. Using available experimental data, we show that mixing variably fractionated dry and wet basalts with similar viscosities followed by crystallization-differentiation in the deep crust reproduces the geochemical characteristics observed in tonalites. Hence, we propose that mixing of damp and wet melts followed by crystallization-differentiation of the newly formed hybrid melt in the deep crust could explain the formation of uniform tonalitic melts at shallower crustal levels in the BVIS. Considering the similar geochemical characteristics of intermediate and felsic igneous rocks from the Sierra Nevada and the Cascades, this process may be more common than previously recognized. 